\title{
Reisen macht krank
}

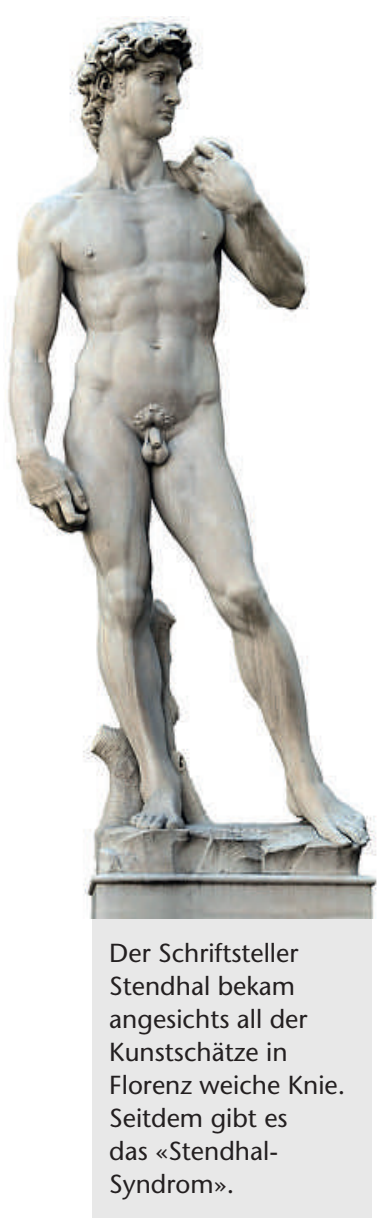

erhard.taverna[at]saez.ch
Erst waren es ärztliche Bulletins aus England, die vor den Geschwindigkeitsexzessen der ersten Eisenbahnen warnten. Fallgeschichten bezeugten irreversible Schäden an Leib und Seele. Trotz seither zunehmendem Tempo sind die befürchteten Epidemien ausgeblieben. Als weit resistenter erwiesen sich Leiden wie die Rache Montezumas und weitere Vergeltungsschläge aus dem Reich der Mikroorganismen, die Reisemedizinern und verwandten Berufen eine solide Existenzgrundlage sichern.

Von Spezialisten weitgehend ignoriert bleiben hingegen, trotz fachärztlicher Publikationen, gewisse Notfälle am Krankenhaus Santa Maria Nuova in Florenz. Ständig werden dort einige Betten für diese akuten Einweisungen freigehalten. Meist handelt es sich um alleinreisende Touristen mit psychosomatischen Komplikationen wie Kreislaufbeschwerden, Denkstörungen, Halluzinationen, Panikattacken oder affektive Störungen in Form von Allmachtsphantasien oder Hassgefühlen. Die meisten davon waren ohne professionelle Führung den Kunstschätzen der Stadt ausgesetzt. Die Psychiaterin Graziella Magherini hat diese Fallbeschreibungen erstmals 1989, nach eingehender Forschung, unter dem Begriff «StendhalSyndrom» bekannt gemacht. 2007 hat die Dottoressa mit einer weiteren Publikation unter besonderer Berücksichtigung der David-Statue von Michelangelo dem Syndrom zu einem zumindest teilweise anerkannten Begriff mit einer spezifischen Diagnose verholfen.

Die Kollegenzunft hat das Stendhal-Syndrom weniger enthusiastisch als die Touristik und die Kunstwelt aufgenommen. Buchautoren und Regisseure haben das Motiv des von der Kunst überwältigten Betrachters in ihren Werken mehrfach umgesetzt. Der Begriff hat Schule gemacht und wird inzwischen auf andere Reiseziele wie Venedig, Jerusalem oder Paris ausgeweitet. Der französische Schriftsteller Stendhal (1783-1842) dient der Medizin als Kronzeuge. Anlässlich einer Florenzreise notierte er: «Ich befand mich in einer Art Ekstase bei dem Gedanken, in Florenz und den Gräbern so vieler Grossen so nahe zu sein. Ich war in Bewunderung der erhabenen Schönheit versunken; ich sah sie aus nächster Nähe und berührte sie fast. Ich war an dem Punkt der Begeisterung angelangt, wo sich die himmlischen Empfindungen, wie sie die Kunst bietet, mit leidenschaftlichen Gefühlen gatten. Als ich die Kirche verliess, klopfte mir das Herz. Mein Lebensquell war versiegt, und ich fürchtete umzufallen.» Wie war das mit dem bekannten Werbespruch: «Napoli vedere e poi morire»? Obwohl jährlich allein in Florenz etwa ein Dutzend Patienten eingeliefert werden, hat Magherini in mehreren Interviews versichert, dass es zu keinen Todesfällen kam. Wahrscheinlich, weil die Betroffenen noch jung waren.

Ähnliches ist aus dem Umkreis von Megalithstätten bekannt. Studien der Landeskliniken Salzburg und der Wiener Krankenhausanstalten aus dem Jahr 2003 berichten von Besuchern mit Pulsrasen und schweren Beinen. Wissenschaftler der Grazer LudwigBoltzmann-Forschungsstelle für Biosensorik haben schon 1995 ortsabhängige Abweichungen des Erdmagnetfelds, sogenannte «geopathogene Zonen», nachgewiesen. Für Wünschelrutengänger eine klare Sache. Die Anhänger der Geomantie sind überzeugt, dass Megalithe auf Knotenpunkten von Kraftlinien errichtet wurden. Das Dragon-Projekt des Ethnologen Paul Deveraux sammelt diese psycho-physischen Befunde, inklusive Berichte überwältigender Träume von Versuchspersonen, die freiwillig in Steinkreisen schlafen. Seit 1988 vereinigt die gemeinnützige Stiftung Experten aus verschiedensten Fachgebieten. Der Name verweist auf Feng Shui, wo der Drache die tellurischen Kräfte symbolisiert. Andere Wissenschaftler haben Resultate herausgefunden, die nicht zur physikalisch orientierten Geomantie passen. Danach wirkt auch eine ganz normale Landschaft auf Menschen ein, je nach Beschaffenheit, als Kraftquelle oder Krankmacher. Bildungsreisen haben in jeder Hinsicht einen Preis. Ist daraus zu schliessen, dass sensible Naturen besser zu Hause bleiben? Wie hat doch schon Blaise Pascal (1623-1692) warnend bemerkt: «Das ganze Unglück der Menschen rührt allein daher, dass sie nicht ruhig in einem Zimmer bleiben.» Heute steht in jedem Zimmer eine Glotze. Doch nicht jeder ist so genial wie der Mathematiker und Philosoph Pascal, der beim Denken seine Ruhe brauchte. Zudem war er kränklich, lebte asketisch und war sehr fromm. Also, soll man jetzt reisen oder nicht? Für den, der unter Flugangst, Seekrankheit, Finanznot und Agoraphobie leidet, ist die Frage schon beantwortet. Der Rest mag sich wohl überlegen, ob er den Meisterwerken aus Kunst, Geschichte und Natur gewachsen ist. Oder auch nicht.

Erhard Taverna 